\title{
12 Lead Continuous ECG
}

National Cancer Institute

\section{Source}

National Cancer Institute. 12 Lead Continuous ECG. NCI Thesaurus. Code C123444.

A continuous electrocardiographic (ECG) recording that utilizes twelve leads, though the lead placement may vary from the standard 12 Lead ECG placement. Examples include, but are not limited to, 12 lead Holter with modified Mason-Likar lead placements, 12 lead exercise ECGs, and 12 lead telemetry systems. 